\title{
Hippocampo-Horn Percentage and Parietal Atrophy Score for Easy Visual Assessment of Brain Atrophy on Magnetic Resonance Imaging in Early- and Late-Onset Alzheimer's Disease
}

\author{
David Silhan*, Olga Pashkovska, Ales Bartos and for the Alzheimer's Disease Neuroimaging \\ Initiative $^{1}$ \\ Department of Neurology, Charles University, Third Faculty of Medicine, Prague, Czech Republic
}

Accepted 10 September 2021

Pre-press 8 October 2021

\begin{abstract}
. according to some studies. MRI visual scales and evaluate their reliability. from 0.90 to 0.99 ). atrophy, parietal atrophy score, parietal atrophy, reliability

\footnotetext{
${ }^{1}$ Data used in preparation of this article were obtained from the Alzheimer's Disease Neuroimaging Initiative (ADNI) database (adni.loni.usc.edu). As such, the investigators within the ADNI contributed to the design and implementation of ADNI and/or provided data but did not participate in analysis or writing of this report. A complete listing of ADNI investigators can be found at: https://adni.loni.usc.edu/wp-content/uploads/how_to_ apply/ADNI_Acknowledgement_List.pdf.
}

Background: Magnetic resonance imaging (MRI) visual scales of brain atrophy are important for differential diagnosis of dementias in routine clinical practice. Atrophy patterns in early- and late-onset Alzheimer's disease (AD) can be different

Objective: Our goal was to assess brain atrophy patterns in early- and late-onset AD using our recently developed simple

Methods: We used Hippocampo-horn percentage (Hip-hop) and Parietal Atrophy Score (PAS) to compare mediotemporal and parietal atrophy on brain MRI among 4 groups: 26 patients with early-onset AD, 21 younger cognitively normal persons, 32 patients with late-onset $\mathrm{AD}$, and 36 older cognitively normal persons. Two raters scored all brain MRI to assess reliability of the Hip-hop and PAS. Brain MRIs were obtained from Alzheimer's Disease Neuroimaging Initiative (ADNI) database.

Results: The patients with early-onset AD had significantly more pronounced mediotemporal and also parietal atrophy bilaterally compared to the controls (both $p<0.01$ ). The patients with late-onset AD had significantly more pronounced only mediotemporal atrophy bilaterally compared to the controls $(p<0.000001)$, but parietal lobes were the same. Intra-rater and inter-rater reliability of both visual scales Hip-hop and PAS were almost perfect in all cases (weighted-kappa value ranged

Conclusion: While mediotemporal atrophy detected using Hip-hop is universal across the whole AD age spectrum, parietal atrophy detected using PAS is worth rating only in early-onset AD. Hip-hop and PAS are very reliable MRI visual scales.

Keywords: Early-onset Alzheimer's disease, hippocampo-horn percentage, late-onset Alzheimer's disease, mediotemporal

${ }^{*}$ Correspondence to: David Silhan, MD, Department of Neurology, Third Faculty of Medicine, Charles University, Ruská 87, 10000 Prague 10, Czech Republic. Tel.: +420 737342109; E-mail: david.silhan@atlas.cz. 


\section{INTRODUCTION}

Brain magnetic resonance imaging (MRI) can support the diagnosis of Alzheimer's disease (AD) [1]. Tissue loss in the mediotemporal area is typical for late-onset $\mathrm{AD}$ (patients older than 65 years) [2-13]. Distribution of atrophy in patients with earlyonset $\mathrm{AD}$ (individuals younger than 65 years) is not so obvious. More pronounced atrophy of the parietal lobes with less affected mediotemporal region could be more typical for these younger patients based on some studies [14-17].

Atrophy of brain structures can be assessed on MRI using quantitative techniques such as manual or automatic segmentation [2, 8, 18-21]. Accuracy and objectivity of these approaches are main adv antages. However, automatic segmentation requires specialized software and manual segmentation is time-consuming. These quantitative techniques detect well-known mediotemporal atrophy in patients with $\mathrm{AD}$ and also parietal atrophy (smaller precuneus and cingulate gyrus) more typical for patients with early-onset $\mathrm{AD}[22,23]$.

MRI visual scales represent easier and faster option to evaluate brain atrophy and thus are more suitable for routine clinical practice [24-26]. Their possible disadvantage can be lower reliability compared to quantitative methods, because evaluations are performed by different raters who can have different experience. Previous studies using MRI visual scales achieved comparable results as studies with quantitative techniques mentioned above [27-30]. The most used visual scales are Scheltens scale for the mediotemporal atrophy and Koedam scale for the parietal atrophy. However, these visual scales may be complicated and time consuming for routine clinical practice.

The aim of our study was to assess parietal and mediotemporal atrophy in patients with early- and late-onset $\mathrm{AD}$ using our simple MRI visual scales. We also wanted to evaluate reliability of these scales. The Parietal Atrophy Score (PAS) for evaluation of the parietal region was introduced in our previous reports [31-33]. Hippocampo-horn percentage for evaluation of the mediotemporal atrophy was developed based on our previous findings [2,3].

We assumed that we will be able to determine and confirm different atrophy patterns in early- and lateonset AD using our new and simple MRI visual scales which could be suitable for routine clinical practice. We believed that these results could be useful in differential diagnosis of neurodegenerative dementias especially AD in clinical field.

\section{MATERIALS AND METHODS}

\section{Visual scale of mediotemporal atrophy}

Hippocampo-horn percentage (Hip-hop) is based on determining the ratio between the hippocampal area and the sum of the hippocampal area and the temporal horn area of the lateral ventricle in percentages on one suitable MRI slice which is clearly defined and is easy to find. The suitable slice is defined as the first coronal MRI slice in the antero-posterior direction where amygdala is no longer visible. Our recent paper describes a detailed explanation how to select this optimal slice for Hip-hop determination [3]. Hip-hop can theoretically range between $0 \%$ (total atrophy - hippocampus is not visible) and $100 \%$ (completely spared structure of the hippocampus), 20-90\% in real clinical practice. More detailed Hip-hop scoring instructions are summarized in the Supplementary Material.

\section{Visual scale of parietal atrophy}

The PAS is based on evaluation of atrophy degree in three parietal lobe structures: sulcus cingularis posterior, precuneus and parietal gyri. Each structure is ranked separately left and right 0 (no atrophy), 1 (borderline finding) or 2 (prominent atrophy). The degree of atrophy in each structure is evaluated on MRI coronal slices in the range of whole parietal lobes. Evaluation of the PAS in antero-posterior direction begins from first slice where cerebellar hemispheres are visible and continues until parietooccipital sulcus first appears. PAS is determined from a combination of atrophy degrees separately in the left and right hemisphere according to specific rating criteria and can be quantified 0 (parietal lobe without atrophy), 1 (border-line atrophy) or 2 (prominent atrophy of the parietal lobe) [31-33]. PAS scoring instructions are summarized in Supplementary Material.

\section{Alzheimer's Disease Neuroimaging Initiative}

Data used in the preparation of this article were obtained from the Alzheimer's Disease Neuroimaging Initiative (ADNI) database (adni.loni.usc.edu), more specifically from ADNI-1, ADNI-GO and ADNI-2 study. The ADNI was launched in 2003 as a public-private partnership, led by Principal Investi- 
gator Michael W. Weiner, MD. The primary goal of ADNI has been to test whether serial MRI, positron emission tomography, other biological markers, and clinical and neuropsychological assessment can be combined to measure the progression of mild cognitive impairment and early AD.

\section{Participants and MRI protocol}

Diagnoses of $\mathrm{AD}$ were established by $\mathrm{ADNI}$ according to the neurological examination, cognitive tests and using the biomarkers of AD. We selected AD patients with mild impairment of cognitive functions (Mini-Mental State Examination (MMSE) $22 \pm 4$ ). Cognitively normal subjects were defined as those with normal neurological examination and normal cognitive test (MMSE 29 \pm 1 ). We divided our participants into those with younger age $(<65$ years) and ones older than 65 years.

We created four groups: 1) patients with late-onset $\mathrm{AD}$ (AD patients older than 65 years), 2) older cognitively normal subjects, 3 ) patients with early-onset $\mathrm{AD}$ (AD patients younger than 65 years), and 4) younger cognitively normal subjects.

We first compared mediotemporal and parietal atrophy using our MRI visual scales (Hip-hop, PAS) between patients with late-onset $\mathrm{AD}$ and older cognitively normal elderly subjects, patients with early-onset $\mathrm{AD}$ and younger cognitively normal persons.

In the second step we compared atrophy between older and younger cognitively normal persons, patients with late- and early-onset $\mathrm{AD}$.

Correlation of the Hip-hop and PAS with age was calculated using all cognitively normal subjects (older and younger group together).

Detailed participant's characteristics are visualized in Table 1. Patients with early- and late-onset AD were age-matched with cognitively normal subjects in both cases. Patients with early- and late-onset AD had equal cognitive impairment according to MMSE scores.

Brain MRI of these patients were obtained from the Alzheimer's Disease Neuroimaging Initiative (ADNI) database. $94 \%$ patients were examined by the following imaging protocol: Acquisition Plane $=$ sagital; Acquisition Type $=3 \mathrm{D} ;$ Coil $=\mathrm{PA}$; Field Strength $=1.5$ tesla; Flip Angle $=8.0$ degree; Manufacturer $=$ SIEMENS; Matrix $\mathrm{X}=192.0$ pixels; Matrix $Y=192.0$ pixels; Matrix $Z=160.0 ;$ Mfg Model = SonataVision; Pixel Spacing $X=1.25 \mathrm{~mm}$; Pixel Spacing $Y=1.25 \mathrm{~mm}$; Pulse Sequence $=I R /$ GR; Slice Thickness $=1.2 \mathrm{~mm}$; $\mathrm{TE}=3.54 \mathrm{~ms}$; $\mathrm{TI}=$ $1000.0 \mathrm{~ms} ; \mathrm{TR}=2400.0 \mathrm{~ms}$; Weighting $=\mathrm{T} 1$.

\section{Characteristics of raters and reliability assessment (intra- and inter-rater agreement)}

Rater 1 was a neurologist with 6-year experience in the assessment of brain atrophy using MRI visual scales. He rated all brain MRI twice with an interval 2 years between evaluations to evaluate intra-rater agreement. The rater was blinded for clinical information (diagnosis, age), for his previous rating and for the rating of second rater. This rater achieved very good intra- and inter-rater agreement with other experienced evaluators in our previous study about the PAS reliability [31]. First scoring of this rater was used to assess differences in brain atrophy between 4 groups.

Rater 2 was a medical doctor and $\mathrm{PhD}$ student with 3 -year experience in the assessment of brain atrophy using MRI visual scales. She rated all brain MRI first to assess inter-rater agreement with rater 1 . She rated 40 brain MRI (10 from each group) after 6 weeks to assess intra-rater agreement. Rater 2 was also blinded for clinical information (diagnosis, age), for her previous rating and for the rating of the first rater. Rater 2 also achieved very good intra- and inter-rater agreement with another evaluators in our previous study about the PAS reliability [31].

Table 1

Characteristics of participants

\begin{tabular}{|c|c|c|c|c|c|c|}
\hline & LOAD & $\mathrm{OCN}$ & $\begin{array}{c}\text { LOAD } \\
\text { versus OCN }\end{array}$ & EOAD & $\mathrm{YCN}$ & $\begin{array}{c}\text { EOAD } \\
\text { versus YCN }\end{array}$ \\
\hline Number of subjects & 32 & 36 & n.a. & 26 & 21 & n.a. \\
\hline Mean age (y) & 80 & 80 & n.s. & 63 & 64 & n.s. \\
\hline MMSE (points) & $22 \pm 4$ & $29 \pm 1$ & $p<0.001$ & $22 \pm 4$ & $29 \pm 1$ & $p<0.001$ \\
\hline Sex (male/female) & $19 / 13$ & $14 / 22$ & n.a. & $14 / 12$ & $11 / 10$ & n.a. \\
\hline
\end{tabular}

LOAD, patients with late-onset Alzheimer's disease; EOAD, patients with early-onset Alzheimer's disease; OCN, old cognitively normal subjects; YCN, young cognitively normal subjects; MMSE, Mini-Mental State Examination; n.s., not significant; n.a., not available/applicable. 


\section{Statistical analysis}

Statistical analysis was performed using software Statistica and Medcalc. We used non-parametric Mann-Whitney U test to compare Hip-hop and PAS scores between the groups.

We also performed Receiver Operating Characteristic (ROC) analysis to determine specificity and sensitivity of our visual scales in diagnosis of earlyand late-onset AD.

Kappa statistics was used to assess intra-rater and inter-rater agreement (reliability).

Spearman's rank correlation coefficient was used to assess correlation of the PAS and Hip-hop with age.

\section{RESULTS}

Comparison of Hip-hop and PAS scores between the patients with $A D$ and the cognitively normal subjects

Patients with late-onset AD had significantly more pronounced mediotemporal atrophy compared to cognitively normal subjects using Hip-hop. No significant difference was found in atrophic changes of the parietal lobes using PAS between these groups (Table 2).

Patients with early-onset AD had significantly more pronounced mediotemporal atrophy using Hiphop and also parietal atrophy using PAS compared to cognitively normal persons (Table 2).

\section{Comparison of Hip-hop and PAS scores between older and younger cognitively normal persons and between the patients with early-and late-onset $A D$}

Older cognitively normal persons had significantly more pronounced mediotemporal atrophy bilaterally compared to the younger cognitively normal subjects, but parietal lobes were the same (Table 2).

Patients with early-onset AD had significantly more pronounced parietal atrophy bilaterally compared to the patients with late-onset AD (Table 2). Patients with late-onset AD had more pronounced mediotemporal atrophy bilaterally compared to the younger patients (Table 2).

Table 2

Comparison of Hip-hop and PAS scores among patients with late- and early-onset AD and younger and older cognitively normal subjects

\begin{tabular}{|c|c|c|c|c|c|c|c|c|}
\hline & $\begin{array}{c}\text { Median } \\
\text { (IQR) }\end{array}$ & $\begin{array}{l}\text { Median } \\
\text { (IQR) }\end{array}$ & $\begin{array}{c}\text { LOAD } \\
\text { versus OCN } \\
p \text { value }\end{array}$ & $\begin{array}{c}\text { Median } \\
\text { (IQR) }\end{array}$ & $\begin{array}{l}\text { EOAD } \\
\text { Median } \\
\text { (IQR) }\end{array}$ & $\begin{array}{c}\text { EOAD } \\
\text { versus YCN } \\
p \text { value }\end{array}$ & $\begin{array}{c}\text { OCN } \\
\text { versus YCN } \\
p \text { value }\end{array}$ & $\begin{array}{c}\text { LOAD } \\
\text { versus EOAD } \\
p \text { value }\end{array}$ \\
\hline Hip-hop right & $78 \%(20 \%)$ & $40 \%(30 \%)$ & $p<0.000001$ & $90 \%(10 \%)$ & $70 \%(40 \%)$ & $p<0.0001$ & $p<0.001$ & $p<0.0001$ \\
\hline Hip-hop left & $80 \%(20 \%)$ & $38 \%(28 \%)$ & $p<0.000001$ & $80 \%(10 \%)$ & $80 \%(30 \%)$ & $p<0.01$ & $p<0.01$ & $p<0.00001$ \\
\hline SCP right & $1(2)$ & $0(1)$ & n.s. & $0(1)$ & $1(1)$ & $p<0.001$ & n.a. & \\
\hline PRE right & $0,5(1)$ & $0(1)$ & n.s. & $1(1)$ & $1(1)$ & n.s. & & \\
\hline PG right & $1(1)$ & $1(1)$ & $p<0.05$ & $1(1)$ & $2(1)$ & $p<0.01$ & & \\
\hline PAS right & $1(1)$ & $1(2)$ & n.s. & $1(2)$ & $2(0)$ & $p<0.01$ & n.s. & $p<0.001$ \\
\hline SCP left & $1(2)$ & $0(1)$ & $p<0.01$ & $0(0)$ & $1(1)$ & $p<0.0001$ & n.a. & \\
\hline PRE left & $0,5(1)$ & $0(1)$ & n.s. & $1(1)$ & $1(1)$ & $p<0.01$ & & \\
\hline PG left & $1(1)$ & $1(1)$ & n.s. & $1(1)$ & $2(1)$ & $p<0.01$ & & \\
\hline PAS left & $1(1)$ & $0,5(2)$ & n.s. & $1(2)$ & $2(1)$ & $p<0.001$ & n.s. & $p<0.001$ \\
\hline
\end{tabular}

LOAD, patients with late-onset Alzheimer's disease; EOAD, patients with early-onset Alzheimer's disease; OCN, old cognitively normal subjects; YCN, young cognitively normal subjects; Hip-hop, Hippocampal-Horn percentage; PAS, Parietal Atrophy Score; SCP, sulcus cingularis posterior; PRE, precuneus; PG, parietal gyri; n.s., not significant; n.a., not available.

Table 3

Sensitivity and specificity of Hip-hop and PAS in diagnosis of early- and late-onset AD

\begin{tabular}{|c|c|c|c|c|c|c|}
\hline & \multicolumn{3}{|c|}{ OCN versus LOAD } & \multicolumn{3}{|c|}{ YCN versus EOAD } \\
\hline & Cut-off & Sensitivity & Specificity & Cut-off & Sensitivity & Specificity \\
\hline Hip-hop left & $\leq 60 \%$ & $88 \%$ & $83 \%$ & $\leq 75 \%$ & $62 \%$ & $91 \%$ \\
\hline Hip-hop right & $\leq 60 \%$ & $84 \%$ & $92 \%$ & $\leq 70 \%$ & $58 \%$ & $100 \%$ \\
\hline PAS left & $\leq 0$ & $50 \%$ & $78 \%$ & $>1$ & $73 \%$ & $71 \%$ \\
\hline PAS right & $\leq 0$ & $44 \%$ & $78 \%$ & $>1$ & $77 \%$ & $62 \%$ \\
\hline
\end{tabular}

LOAD, late-onset Alzheimer's disease; EOAD, early-onset Alzheimer's disease; OCN, old cognitively normal subjects; YCN, young cognitively normal subjects; Hip-hop, Hippocampal-Horn percentage; PAS, Parietal Atrophy Score. 


\section{Correlation of the Hip-hop and PAS with age in cognitively normal subjects}

We found significant negative correlation between the Hip-hop and age on the right $(\mathrm{r}=-0.43, p<0.001)$ and also on the left $(\mathrm{r}=-0.34, p<0.01)$.

Correlation between the PAS and age was not significant on the right $(\mathrm{r}=0.11, p=0.40)$ or on the left $(\mathrm{r}=0.22, p=0.07)$

\section{Sensitivity and specificity of Hip-hop and PAS in} diagnosis of early-and late-onset $A D$

Hip-hop achieved high specificity and sensitivity in diagnosis of late-onset AD. Specificity of the Hiphop in diagnosis of early-onset $\mathrm{AD}$ was also high, but sensitivity was lower (Table 3).

PAS achieved good specificity and sensitivity in diagnosis of early-onset AD. Specificity of the PAS in diagnosis of late-onset $\mathrm{AD}$ was also quite good, but sensitivity was low (Table 3 ).

Hip-hop is significantly better visual scale in diagnosis of late-onset AD compared to PAS according to the comparison of the areas under receiver operating characteristic curves (Table 4). We did not find significant difference between Hip-hop and PAS in diagnosis of early-onset AD (Table 4).

\section{Reliability of Hip-hop and PAS}

Intra-rater agreement of the neurologist and the medical doctor in Hip-hop and PAS were almost perfect in all cases. Inter-rater agreement between the neurologist and the medical doctor in Hip-hop and PAS were also almost perfect in all cases. Weightedkappa values are summarized in Table 5.

We also used first scoring of Rater 2 (medical doctor) to assess differences among our four groups: patients with late-onset $\mathrm{AD}$, older cognitively normal subjects, patients with early-onset $\mathrm{AD}$, and younger cognitively normal subjects. The results calculated from medical doctor scoring matched the results calculated from neurologist scoring, which are used in our manuscript. Significant differences in mediotemporal and parietal atrophy were between patients with early-onset AD and controls. Significant difference was only in mediotemporal and not parietal atrophy between patients with late-onset $\mathrm{AD}$ and controls. Results of comparison of late- and early-onset $\mathrm{AD}$ patients, and older and younger cognitively normal subjects were also same when we used scoring of Rater 2 in statistics.

\section{DISCUSSION}

Our results with the PAS and Hip-hop in AD patients with mild impairment of cognitive functions confirmed the hypothesis based on some previous studies that mediotemporal atrophy is typical for both late- and early-onset $\mathrm{AD}$, but less pronounced in these younger patients [14-17]. Parietal atrophy seems to be more typical for patients with early-onset AD compared to late-onset $\mathrm{AD}[14-17,22,27]$.

We proved that our simple MRI visual scales Hiphop and PAS are very reliable with almost perfect

Table 4

Comparison of areas under receiver operating characteristics curves of PAS and Hip-hop in late- and early-onset AD

\begin{tabular}{llcccccc}
\hline & & $\begin{array}{c}\text { Hip-hop } \\
\text { right }\end{array}$ & $\begin{array}{c}\text { PAS } \\
\text { right }\end{array}$ & $\begin{array}{c}\text { Comparison } \\
\text { of AUC }\end{array}$ & $\begin{array}{c}\text { Hip-hop } \\
\text { left }\end{array}$ & $\begin{array}{c}\text { PAS } \\
\text { left }\end{array}$ & $\begin{array}{c}\text { Comparison } \\
\text { of AUC }\end{array}$ \\
\hline OCN versus LOAD & AUC & 0.93 & 0.60 & $p<0.0001$ & 0.93 & 0.63 & $p<0.0001$ \\
YCN versus EOAD & AUC & 0.85 & 0.71 & n.s. & 0.76 & 0.76 & n.s. \\
\hline
\end{tabular}

LOAD, patients with late-onset Alzheimer's disease; EOAD, patients with early-onset Alzheimer's disease; OCN, old cognitively normal subjects; YCN, young cognitively normal subjects; n.s., not significant; Hip-hop, Hippocampo-horn percentage; PAS, Parietal Atrophy Score; AUC, Area Under the ROC Curve; ROC, Receiver Operating Characteristic.

Table 5

Intra-rater and inter-rater agreement in Hip-hop and PAS expressed as weighted-kappa value

\begin{tabular}{|c|c|c|c|c|}
\hline & $\begin{array}{l}\text { weighted-kappa } \\
\text { value for Hip-hop } \\
\text { right/left }\end{array}$ & $\begin{array}{c}\text { weighted kappa } \\
\text { value for PAS } \\
\text { right/left }\end{array}$ & $\begin{array}{l}\text { weighted-kappa } \\
\text { value for Hip-hop } \\
\text { right/left }\end{array}$ & $\begin{array}{c}\text { weighted kappa } \\
\text { value for PAS } \\
\text { right/left }\end{array}$ \\
\hline Rater & $\begin{array}{l}\text { neurologist } \\
\text { 1. rating }\end{array}$ & $\begin{array}{l}\text { neurologist } \\
\text { 1. rating }\end{array}$ & $\begin{array}{l}\text { medical doctor } \\
\text { 2.rating }\end{array}$ & $\begin{array}{l}\text { medical doctor } \\
\text { 2. rating }\end{array}$ \\
\hline $\begin{array}{l}\text { neurologist } 2 \text {. rating } \\
\text { medical doctor } 1 \text {. rating }\end{array}$ & $\begin{array}{l}0.97 / 0.96 \\
0.94 / 0.93\end{array}$ & $\begin{array}{l}0.95 / 0.97 \\
0.90 / 0.96\end{array}$ & $\begin{array}{c}\text { n.a. } \\
0.94 / 0.91\end{array}$ & $\begin{array}{c}\text { n.a. } \\
0.91 / 0.99\end{array}$ \\
\hline
\end{tabular}

Hip-hop, Hippocampo-horn percentage; PAS, Parietal Atrophy Score; n.a., not available. 
intra-rater and inter-rater agreement. These results are even better than reliability results of PAS from our previous study [31]. We think that explanation of this improvement can be effect of learning. Both raters in our current study also participated in reliability assessment of the PAS in our previous paper and have gained more experience with this visual scale.

The results (differences in atrophy between our four groups) calculated from medical doctor scoring matched the results calculated from neurologist scoring, which are used in our manuscript and mentioned above. The results are consistent because inter-rater reliability of our visual scales was almost perfect.

Moreover, Hip-hop and PAS are used only in coronal MRI slices, which can spare the time during atrophy evaluation in routine clinical practice. PAS has been recently introduced in our studies [31-33]. This is the first report of Hip-hop estimated in an optimal coronal MRI slice described in the recent paper [3]. We consider our new easily applicable and very reliable visual scales as the main strengths of our study.

Some limitations of our study should be mentioned. Diagnoses of AD were not confirmed at autopsy. However, diagnoses were established based on clinical examination with support of novel biomarkers of AD. Presence of atypical forms of AD in our sample from ADNI is unknown. They can have different atrophy patterns. We did not use a quantitative method to support accuracy of our visual scales in this study. We do not have clear explanation why the atrophy of sulcus cingularis left and parietal gyri right was significantly more pronounced in older cognitively normal subjects compared to the patients with late-onset AD. PAS should be used mainly for diagnosis of early-onset AD.

Mediotemporal atrophy assessed using Hip-hop is more pronounced in older cognitively normal subjects according to the correlation of the Hip-hop with age and comparison of older and younger cognitively normal group. This should be taken into account during evaluation in clinical practice. Our control groups of cognitively normal persons were age-matched with $\mathrm{AD}$ patients. It means that our results should not be influenced by this phenomenon. Parietal atrophy assessed using PAS was not different between older and younger controls. Correlation of the PAS with age also was not significant. This confirms results with the PAS from our previous study [32]. It could mean that more pronounced atrophy in this region is probably not accompanied with normal aging and should be considered as pathologic.
Hip-hop can support the diagnosis of both earlyand late-onset AD. PAS can support mainly the diagnosis of early-onset AD. Hip-hop seems to be better visual scale in diagnosis of late-onset $\mathrm{AD}$ compared to PAS because parietal atrophy is negligible and comparable in these older AD patients and controls [33]. PAS could be useful in differential diagnosis between frontotemporal lobar degeneration (FTLD) and early-onset AD. Mediotemporal atrophy is typical for these early-onset dementias, but parietal atrophy is not typical for FTLD where frontal lobes are usually more affected [34-38].

Different patterns of brain atrophy in early- and late-onset $\mathrm{AD}$ may be related to different clinical presentations of these subtypes. Recent episodic memory is usually mostly affected in patients with late-onset $\mathrm{AD}$ (greater hippocampal atrophy). Atypical clinical forms with early decline in other cognitive abilities, e.g. visuospatial functions are more frequent in patients with early-onset $\mathrm{AD}$ (greater parietal atrophy) [39-41].

We believe that Hip-hop and PAS could be useful tools in differential diagnosis of neurodegenerative dementias especially $\mathrm{AD}$ in routine clinical practice.

\section{ACKNOWLEDGMENTS}

Data collection and sharing for this project was funded by the Alzheimer's Disease Neuroimaging Initiative (ADNI) (National Institutes of Health Grant U01 AG024904) and DOD ADNI (Department of Defense award number W81XWH-12-2-0012). ADNI is funded by the National Institute on Aging, the National Institute of Biomedical Imaging and Bioengineering, and through generous contributions from the following: AbbVie, Alzheimer's Association; Alzheimer's Drug Discovery Foundation; Araclon Biotech; BioClinica, Inc.; Biogen; BristolMyers Squibb Company; CereSpir, Inc.; Cogstate; Eisai Inc.; Elan Pharmaceuticals, Inc.; Eli Lilly and Company; EuroImmun; F. Hoffmann-La Roche Ltd and its affiliated company Genentech, Inc.; Fujirebio; GE Healthcare; IXICO Ltd.; Janssen Alzheimer Immunotherapy Research \& Development, LLC.; Johnson \& Johnson Pharmaceutical Research \& Development LLC.; Lumosity; Lundbeck; Merck \& Co., Inc.; Meso Scale Diagnostics, LLC.; NeuroRx Research; Neurotrack Technologies; Novartis Pharmaceuticals Corporation; Pfizer Inc.; Piramal Imaging; Servier; Takeda Pharmaceutical Company; and Transition Therapeutics. The Canadian Institutes 
of Health Research is providing funds to support ADNI clinical sites in Canada. Private sector contributions are facilitated by the Foundation for the National Institutes of Health (www.fnih.org). The grantee organization is the Northern California Institute for Research and Education, and the study is coordinated by the Alzheimer's Therapeutic Research Institute at the University of Southern California. ADNI data are disseminated by the Laboratory for Neuro Imaging at the University of Southern California.

This study was supported by PROGRES Q 35 from Charles University, the project "Sustainability for the National Institute of Mental Health," under grant number [LO1611] from from the Ministry of Education, Youth and Sports, grants from Ministry of Health [NV18-07-00272 and NV19-04-00090] and Program Trio [FV40032] (CleverAge Biota) from Ministry of Industry and Trade. All rights reserved. Project 260533/SVV/2020.

Authors' disclosures available online (https:// www.j-alz.com/manuscript-disclosures/21-0372r3).

\section{SUPPLEMENTARY MATERIAL}

The supplementary material is available in the electronic version of this article: https://dx.doi.org/ 10.3233/JAD-210372.

\section{REFERENCES}

[1] Avila J, Perry G (2020) A multilevel view of the development of Alzheimer's disease. Neuroscience 457, 283-293.

[2] Bartos A, Gregus D, Ibrahim I, Tintera J (2019) Brain volumes and their ratios in Alzheimer's disease on magnetic resonance imaging segmented using FreeSurfer 6.0. Psychiatry Res Neuroimaging 287, 70-74.

[3] Zach P, Bartos A, Lagutina A, Wurst Z, Gallina P, Rai T, Kieslich K, Riedlová J, Ibrahim I, Tintěra J, Mrzilkova J (2020) Easy identification of optimal coronal slice on brain magnetic resonance imaging to measure hippocampal area in Alzheimer's disease patients. Biomed Res Int 2020, 5894021.

[4] Jack CR Jr, Shiung MM, Gunter JL, O'Brien PC, Weigand SD, Knopman DS, Boeve BF, Ivnik RJ, Smith GE, Cha RH, Tangalos EG, Petersen RC (2004) Comparison of different MRI brain atrophy rate measures with clinical disease progression in AD. Neurology 62, 591-600.

[5] Fennema-Notestine C, McEvoy LK, Hagler DJ Jr, Jacobson MW, Dale AM, The Alzheimer's Disease Neuroimaging Initiative (2009) Structural neuroimaging in the detection and prognosis of pre-clinical and early AD. Behav Neurol 21, 3-12.

[6] Liu Y, Paajanen T, Zhang Y, Westman E, Wahlund LO, Simmons A, Tunnard C, Sobow T, Mecocci P, Tsolaki M, Vellas B, Muehlboeck S, Evans A, Spenger C, Lovestone S, Soininen H, AddNeuroMed Consortium (2010) Analysis of regional MRI volumes and thicknesses as predictors of conversion from mild cognitive impairment to Alzheimer's disease. Neurobiol Aging 31, 1375-1385.

[7] Vemuri P, Jack CR (2010) Role of structural MRI in Alzheimer's disease. Alzheimers Res Ther 2, 23.

[8] Mrzílkova J, Koutela A, Kutova M, Patzelt M, Ibrahim I, Al-Kayssi D, Bartos A, Ripova D, Čermáková P, Zach P (2014) Hippocampal spatial position evaluation on MRI for research and clinical practice. PLoS One 9, e115174.

[9] Ten Kate M, Barkhof F, Boccardi M, Visser PJ, Jack CR Jr, Lovblad KO, Frisoni GB, Scheltens P, the Geneva Task Force for the Roadmap of Alzheimer's Biomarkers (2017) Clinical validity of medial temporal atrophy as a biomarker for Alzheimer's disease in the context of a structured 5-phase development framework. Neurobiol Aging 52, 167-182.

[10] Zeng Q, Li K, Luo X, Wang S, Xu X, Li Z, Zhang T, Liu X, Fu Y, Xu X, Wang C, Wang T, Zhou J, Liu Z, Chen Y, Huang P, Zhang M, and for the Alzheimer's Disease Neuroimaging Initiative (2021) Distinct atrophy pattern of hippocampal subfields in patients with progressive and stable mild cognitive impairment: a longitudinal MRI study. J Alzheimers Dis 79, 237-247.

[11] Giesel FL, Hahn HK, Thomann PA, Widjaja E, Wignall E, von Tengg-Kobligk H, Pantel J, Griffiths PD, Peitgen HO, Schroder J, Essig M (2006) Temporal horn index and volume of medial temporal lobe atrophy using a new semiautomated method for rapid and precise assessment. Am J Neuroradiol 27, 1454-1458.

[12] Teipel SJ, Pruessner JC, Faltraco F, Born C, Rocha-Unold M, Evans A, Möller HJ, Hampel H (2006) Comprehensive dissection of the medial temporal lobe in AD: Measurement of hippocampus, amygdala, entorhinal, perirhinal and parahippocampal cortices using MRI. J Neurol 253, 794-800.

[13] Teipel S, Kilimann I, Thyrian JR, Kloppel S, Hoffmann W (2018) Potential role of neuroimaging markers for early diagnosis of dementia in primary care. Curr Alzheimer Res 15, 18-27.

[14] Ishii K, Kawachi T, Sasaki H, Kono AK, Fukuda T, Kojima Y, Mori E (2005) Voxel-based morphometric comparison between early- and late-onset mild Alzheimer's disease and assessment of diagnostic performance of $\mathrm{Z}$ score images. Am J Neuroradiol 26, 333-340.

[15] Frisoni GB, Pievani M, Testa C, Sabattoli F, Bresciani L, Bonetti M, Beltramello A, Hayashi KM, Toga AW, Thompson PM (2007) The topography of grey matter involvement in early and late onset Alzheimer's disease. Brain 130, 720-730.

[16] Shiino A, Watanabe T, Kitagawa T, Kotani E, Takahashi J, Morikawa S, Akiguchi I (2008) Different atrophic patterns in early- and late-onset Alzheimer's disease and evaluation of clinical utility of a method of regional z-score analysis using voxel-based morphometry. Dement Geriatr Cogn Disord 26, 175-186.

[17] Lehmann M, Koedam EL, Barnes J, Bartlett JW, Ryan NS, Pijnenburg YAL, Barkhof F, Wattjes MP, Scheltens P, Fox NC (2012) Posterior cerebral atrophy in the absence of medial temporal lobe atrophy in pathologically-confirmed Alzheimer's disease. Neurobiol Aging 33, 627.e1-627.e12.

[18] Rathakrishnan BG, Doraiswamy PM, Petrella JR (2013) Science to Practice: Translating automated brain MRI volumetry in Alzheimer's disease from research to routine diagnostic use in the work-up of dementia. Front Neurol 4, 216. 
[19] Mulder ER, de Jong RA, Knol DL, van Schijndel RA, Cover KS, Visser PJ, Barkhof F, Vrenken H, Alzheimer's Disease Neuroimaging Initiative (2014) Hippocampal volume change measurement: Quantitative assessment of the reproducibility of expert manual outlining and the automated methods FreeSurfer and FIRST. Neuroimage 92, 169-181

[20] Cover KS, van Schijndel RA, Versteeg A, Leung KK, Mulder ER, Jong RA, Visser PJ, Redolfi A, Revillard J, GrenierB, Manset D, Damangir S, Bosco P, Vrenken H, van Dijk BW, Frisoni GB, Barkhof F (2016) Reproducibility of hippocampal atrophy rates measured with manual, FreeSurfer, AdaBoost, FSL/FIRST and the MAPS-HBSI methods in Alzheimer's disease. Psychiatry Res 252, 26-35.

[21] Menendez-Gonzalez M, de Celis Alonso B, Salas-Pacheco J, Arias-Carrion O (2015) Structural neuroimaging of the medial temporal lobe in Alzheimer's disease clinical trials. J Alzheimers Dis 48, 581-589.

[22] Karas G, Scheltens P, Rombouts S, van Schijndel R, Klein M, Jones B, van der Flier W, Vrenken H, Barkhof F (2007) Precuneus atrophy in early-onset Alzheimer's disease: A morphometric structural MRI study. Neuroradiology 12, 967-976

[23] Möller C, Vrenken H, Jiskoot L, Versteeg A, Barkhof F, Scheltens P, van der Flier WM (2013) Different patterns of gray matter atrophy in early- and late-onset Alzheimer's disease. Neurobiol Aging 8, 2014-2022.

[24] Harper L, Barkhof F, Fox NC, Schott JM (2015) Using visual rating to diagnose dementia: A critical evaluation of MRI atrophy scales. J Neurol Neurosurg Psychiatry 86, 12251233.

[25] Harper L, Fumagalli GG, Barkhof F, Scheltens P, O'Brien JT, Bouwman F, Burton EJ, Rohrer JD, Fox NC, Ridgway GR, Schott JM (2016) MRI visual rating scales in the diagnosis of dementia: Evaluation in 184 post-mortem confirmed cases. Brain 139, 1211-1225.

[26] Rhodius-Meester HFM, Benedictus MR, Wattjes MP, Barkhof F, Scheltens P, Muller M, van der Flier WM (2017) MRI visual ratings of brain atrophy and white matter hyperintensities across the spectrum of cognitive decline are differently affected by age and diagnosis. Front Aging Neurosci $9,117$.

[27] Koedam E, Lehmann M, van der Flier WM, Scheltens P, Pijnenburg YA, Fox N, Barkhof F, Wattjes MP (2011) Visual assessment of posterior atrophy development of a MRI rating scale. Eur Radiol 21, 2618-2625.

[28] Falgás N, Balasa M, Bargalló N, Borrego-Écija S, RamosCampoy O, Fernández-Villullas G, Bosch B, Olives J, Tort-Merino A, Antonell A, Castellví M, Allen IE, SánchezValle R, Lladó A (2020) Diagnostic accuracy of MRI visual rating scales in the diagnosis of early onset cognitive impairment. J Alzheimers Dis 73, 1575-1583.
[29] Scheltens P, Leys D, Barkhof F, Huglo D, Weinstein HC, Vermersch P, Kuiper M, Steinling M, Wolters E, Valk J (1992) Atrophy of medial temporal lobes on MRI in "probable" Alzheimer's disease and normal ageing: Diagnostic value and neuropsychological correlates. J Neurol Neurosurg Psychiatry 55, 967-972.

[30] Wahlund L, Julin P, Johansson S, Scheltens P (2000) Visual rating and volumetry of the medial temporal lobe on magnetic resonance imaging in dementia: A comparative study. J Neurol Neurosurg Psychiatry 69, 630-635.

[31] Silhan D, Bartos A, Mrzilkova J, Pashkovska O, Ibrahim I, Tintera J (2020) The parietal atrophy score on brain magnetic resonance imaging is a reliable visual scale. Curr Alzheimer Res 17, 534-539.

[32] Silhan D, Ibrahim I, Tintera J, Bartos A (2018) Parietal atrophy score on magnetic resonance imaging of the brain in normally aging people. Cesk Slov Neurol N 81, 414-419.

[33] Silhan D, Ibrahim I, Tintera J, Bartos A (2019) Magnetic resonance imaging showing parietal atrophy of the brain in late-onset Alzheimer's disease. Cesk Slov Neurol N 82, 91-95.

[34] Galton CJ, Patterson K, Graham K, Lambon-Ralph MA, Williams G, Antoun N, Sahakian BJ, Hodges JR (2001) Differing patterns of temporal atrophy in Alzheimer's disease and semantic dementia. Neurology 57, 216-225.

[35] Thompson SA, Patterson K, Hodges JR (2003) Left/right asymmetry of atrophy in semantic dementia: Behavioralcognitive implications. Neurology 61, 1196-1203.

[36] Boccardi M, Laakso MP, Bresciani L, Galluzzi S, Geroldi C, Beltramello A, Soininen H, Frisoni GB (2003) The MRI pattern of frontal and temporal brain atrophy in fronto-temporal dementia. Neurobiol Aging 1, 95-103.

[37] Rohrer JD (2012) Structural brain imaging in frontotemporal dementia. Biochim Biophys Acta 3, 325-332.

[38] Bocchetta M, Iglesias JE, Scelsi MA, Cash DM, Cardoso MJ, Modat M, Altmann A, Ourselin S, Warren JD, Rohrer JD (2018) Hippocampal subfield volumetry: differential pattern of atrophy in different forms of genetic frontotemporal dementia. J Alzheimers Dis 64, 497-504.

[39] van der Flier WM, Pijnenburg YA, Fox NC, Scheltens P (2011) Early-onset versus late-onset Alzheimer's disease: The case of the missing APOE $\varepsilon 4$ allele. Lancet Neurol 3, 280-288.

[40] Koedam E, Lauffer V, Vlies A, Flier W, Scheltens Ph, Pijnenburg Y (2010) Early-versus late-onset Alzheimer's disease: more than age alone. J Alzheimers Dis 19, 14011408.

[41] Tellechea P, Pujol N, Esteve-Belloch P, Echeveste B, GarcíaEulate MR, Arbizu J, Riverol M (2018) Early- and late-onset Alzheimer disease: Are they the same entity? Neurologia 4, 244-253. 